\title{
вмJ Global Health What drives political commitment for nutrition? A review and framework synthesis to inform the United Nations Decade of Action on Nutrition
}

\author{
Phillip Baker, ${ }^{1}$ Corinna Hawkes, ${ }^{2}$ Kate Wingrove, ${ }^{1}$ Alessandro Rhyl Demaio, ${ }^{3}$ \\ Justin Parkhurst, ${ }^{4}$ Anne Marie Thow, ${ }^{5}$ Helen Walls ${ }^{6,7}$
}

\begin{abstract}
To cite: Baker P, Hawkes C, Wingrove $\mathrm{K}$, et al. What drives political commitment for nutrition? A review and framework synthesis to inform the United Nations Decade of Action on Nutrition. BMJ Glob Health 2018;0:e000485. doi:10.1136/ bmjgh-2017-000485
\end{abstract}

Handling editor Valery Ridde

- Additional material is published online only. To view, please visit the journal online (http://dx.doi.org/10.1136/ bmjgh-2017-000485).

Received 20 July 2017 Revised 10 January 2018 Accepted 10 January 2018

Check for updates

For numbered affiliations see end of article.

Correspondence to Dr Phillip Baker; phil.baker@deakin.edu.au

\section{ABSTRACT}

Introduction Generating country-level political commitment will be critical to driving forward action throughout the United Nations Decade of Action on Nutrition (2016-2025). In this review of the empirical nutrition policy literature, we ask: what factors generate, sustain and constrain political commitment for nutrition, how and under what circumstances? Our aim is to inform strategic 'commitment-building' actions.

Method We adopted a framework synthesis method and realist review protocol. An initial framework was derived from relevant theory and then populated with empirical evidence to test and modify it. Five steps were undertaken: initial theoretical framework development; search for relevant empirical literature; study selection and quality appraisal; data extraction, analysis and synthesis and framework modification.

Results 75 studies were included. We identified 18 factors that drive commitment, organised into five categories: actors; institutions; political and societal contexts; knowledge, evidence and framing; and, capacities and resources. Irrespective of country-context, effective nutrition actor networks, strong leadership, civil society mobilisation, supportive political administrations, societal change and focusing events, cohesive and resonant framing, and robust data systems and available evidence were commitment drivers. Low-income and middle-income country studies also frequently reported international actors, empowered institutions, vertical coordination and capacities and resources. In upper-middle-income and high-income country studies, private sector interference frequently undermined commitment.

Conclusion Political commitment is not something that simply exists or emerges accidentally; it can be created and strengthened over time through strategic action. Successfully generating commitment will likely require a core set of actions with some context-dependent adaptations. Ultimately, it will necessitate strategic actions by cohesive, resourced and strongly led nutrition actor networks that are responsive to the multifactorial, multilevel and dynamic political systems in which they operate and attempt to influence. Accelerating the formation and effectiveness of such networks over the Nutrition Decade should be a core task for all actors involved.

\section{INTRODUCTION}

Malnutrition-'an abnormal physiological condition caused by inadequate, unbalanced or excessive consumption of macronutrients and/or micronutrients' ${ }^{1,}$ p53 - is a leading driver of global death and disability. In 2014 462 million adults were underweight, 2 billion micronutrient deficient and 1.9 billion overweight or obese. $^{2}$ In 2016, stunting (low height for age) affected 155 million children under 5 years of age, wasting (low weight for height) 52 million and overweight (high weight for height) a further 41 million. ${ }^{3}$ In 2011, nutrition-related factors contributed to 3.1 million or $45 \%$ of all deaths in children under 5 years of age. ${ }^{3}$ In short, malnutrition affects one in three people in the world and leaves no nation untouched. ${ }^{4}$

The global nutrition situation is becoming more complex. Rapid nutritional change in many countries is precipitating a 'doubleburden' of malnutrition, with high rates of undernutrition coexisting with overweight, obesity and diet-related non-communicable diseases (NCDs) within populations, households and individuals. ${ }^{4} 5$ People who are malnourished are more likely to die younger, suffer disability, live in poverty, have impaired physical and cognitive development and reduced performance at school and work. ${ }^{4}$ Conversely, good nutrition provides a bedrock for the economic and social development of nations; all of the Sustainable Development Goals both influence, and are influenced by, nutrition.

Global-level ambition for tackling 'malnutrition in all its forms' is strong. The declaration of 2016-2025 as the United Nations Decade of Action on Nutrition (the Nutrition Decade) and the positioning of nutrition within Sustainable Development Goal 2 


\section{Key questions}

\section{What is already known about this topic?}

- Global-level ambition for tackling 'malnutrition in all its forms' is strong - the 2016-2025 United Nations Decade of Action on Nutrition (the Nutrition Decade) is testament to this.

- However, without political commitment at the country-level the policies, programmes and resources required to reduce and eliminate malnutrition in all its forms are unlikely to be adopted, effectively implemented and sustained.

- Recent advances in the political economy of nutrition literature reveal a complex web of factors that drive political commitment across different country contexts and forms of malnutrition. An in-depth understanding of these factors can inform strategic 'commitment-building' actions over the Nutrition Decade.

\section{What are the new findings?}

- In this review of the empirical nutrition policy literature, we ask the question: what factors generate, sustain and constrain political commitment for nutrition within countries, how and under what circumstances?

- Overall, 18 factors were identified and organised into five categories: actors; institutions; political and societal contexts; knowledge, evidence and framing; and capacities and resources.

- The identified factors were strongly interdependent and contextdependent, supporting the need to understand the drivers of political commitment within a non-linear and dynamic model of change.

\section{How might this impact practice?}

- Effective strategies for generating and sustaining political commitment over the Nutrition Decade are likely to involve a set of core actions but with some context-dependent adaptations.

- Ultimately, sustained actions by cohesive, responsive and strongly led nutrition actor networks with the strategic and organisational capacities for effective commitment-building are needed.

- Accelerating the development of such networks should be a core task for all actors involved, including international development partners.

(Target 2.2 is ending all forms of malnutrition by 2030) are testament to this. These build on the World Health Assembly's six targets on maternal, infant and young child nutrition and targets on diet-related NCDs (together, the 'global targets'). The technical solutions for achieving these goals and targets exist, including nutrition-specific and nutrition-sensitive interventions that are cost-effective and backed by evidence. ${ }^{6}$

Converting global ambition into on-the-ground reductions in malnutrition will, however, require more than technical know-how. It will also demand political commitment for the sustained mobilisation of national and subnational political systems, policy processes and resources for improved nutrition. ${ }^{4-9}$ The Global Nutrition Report and other monitoring efforts reveal the scope of this challenge-some countries are making progress towards achieving the global targets (particularly on child stunting and wasting), but the large majority are off-track due to shortfalls in governance, policy and programming responses. ${ }^{410}$ In essence, there is a significant gap between current levels of commitment and that needed to drive coherent action for achieving results. ${ }^{4}$

A growing body of empirical research, much of it grounded in political science, describes why and how nutrition has come to receive political commitment in some jurisdictions but has been neglected or systematically ignored in others. Important reviews of this literature exist, focusing on specific nutrition issues or country-contexts. ${ }^{891112}$ With an aim of informing commitment-building actions over the Nutrition Decade, we extend this earlier work by reviewing and synthesising the literature relevant to all forms of malnutrition and country-contexts. We ask the question: what factors generate, sustain and constrain political commitment for nutrition within countries, how and under what circumstances?

\section{Defining political commitment}

We adopt a definition of political commitment as 'the intent and sustained actions over time by societal actors to achieve the objective of reducing and eliminating the manifestations and causes of (malnutrition)'. ${ }^{13 p 282}$ Or more simply, it is 'the will to act and keep on acting until the job is done'. ${ }^{7 \mathrm{pXIV}}$ From this perspective, achieving political commitment is more than generating attention to malnutrition or getting it onto a government agenda. It further involves the mobilisation of political systems and institutions, adopting policies, allocating resources and coordinating responses for as long as necessary to ensure results. ${ }^{79} 13-15$

Five inter-related forms of commitment can be identified in the literature on nutrition's political economy (table 1). Commitment-building, the non-linear and dynamic process by which commitment is generated, ${ }^{7}$ occurs through the deliberate actions of nutrition actor networks - the individuals and organisations operating within a jurisdiction with a shared interest in attenuating malnutrition and who act collectively to do so. ${ }^{9}{ }^{15}$ Such networks may be considered effective when they are capable of generating and sustaining rhetorical, institutional and operational forms of commitment, leveraging embedded commitments and ultimately achieving commitment that is system-wide. ${ }^{15}$

\section{METHODS \\ Review method}

We made several considerations in selecting the review method: the complex nature of political systems, the theoretically guided qualitative case study designs typically used in food and nutrition political analyses, and our aim of describing the multifactorial, interdependent and context-dependent drivers of political commitment rather than a simple description of listed variables. On this basis, we adopted a framework synthesis method ${ }^{16}{ }^{17}$ suitable for reviewing qualitative research on applied policy topics, and adapted the Realist And Meta-narrative Evidence Synthesis: Evolving Standards (RAMESES) standards for reporting purposes. ${ }^{1819}$ 
Table 1 Five forms of political commitment

Form Description

[1] Rhetorical commitment Statements made by members of the executive and legislative branches of government, and/ or those outside of government with whom they are closely associated (eg, donors, civil society leaders) recognising malnutrition as a serious problem, and that concerted action is both needed and forthcoming. ${ }^{715202451}$ A rhetorical commitment may be a 'symbolic gesture' only, especially when the political costs of inaction are low. Or, when genuine, such commitments may reach a government's 'decision-agenda' and be converted into [2] via directives for governmental and societal action.

[2] Institutional commitment The conversion of [1] into substantive policy infrastructure including institutions responsible for coordinating actions, the adoption of enabling legislation, policies and policy instruments commensurate with the severity of the problem, ${ }^{24}{ }^{51}$ and the commitment of mid-level bureaucrats responsible for coordinating action. ${ }^{724}$ Institutions and policies can, however, be underpowered, inadequately resourced and have limited impact. This can trap nutrition in a 'lowpriority cycle' as 'lack of commitment breeds lack of impact breeds lack of commitment'. 8,p7

[3] Operational commitment The conversion of [1] + [2] into on-the-ground actions including the sustained allocation of human, technical and financial resources, the effective coordination of all actors involved along national to subnational implementation pathways and the commitment of street-level managers and implementation teams. ${ }^{245152}$ Limited operational commitment can lead to implementation failure, thereby undermining sustained commitment and further trapping nutrition in a lowpriority cycle. ${ }^{7}$

[4] Embedded commitment When commitment to address issues indirectly related to nutrition (eg, economic development, social protection, hunger reduction initiatives) inadvertently achieves positive nutrition outcomes, referred to as 'nutrition success without nutrition-specific action'. ${ }^{53 \mathrm{p} 26}$ This can create opportunities for nutrition actors when they are capable of sensitising or positioning nutrition within these broader or related policy agendas, thus further catalysing the commitment-building process and forms. ${ }^{1-3} 5253$

$\begin{array}{ll}\text { [5] System-wide } & \text { The achievement of [1]+[2]+[3]+[4] involving all actors operating within a nutrition system } \\ \text { commitment } & \text { including communities, families and individual citizens. }{ }^{715} \text { When achieved, system-wide } \\ \text { commitment can create a powerful reinforcing feedback-loop that institutionalises and sustains } \\ \text { long-term policy and programme responses. To be effective, efforts must be sustained and } \\ \text { recalibrated in response to emerging opposition and demands, changing conditions and } \\ \text { implementation challenges. }{ }^{71315}\end{array}$

This involved formulating a theoretical framework of factors influencing political commitment and modifying it in response to extracted data to result in a revised framework including modified and new factors. We proceeded via five steps: (i) development of a framework integrating several theories on the determinants of political commitment; (ii) a search for relevant empirical literature; (iii) study selection and quality appraisal; (iv) extraction, analysis and synthesis of data and ( $v$ ) population and modification of the framework. A review protocol was registered (PROSPERO 2016:CRD42016046015).

\section{Initial theoretical framework development}

A scoping review of scholarly and grey literature was undertaken in July 2016 to identify relevant theories, to explicate the phenomena under study and identify search terms. To guide our initial conceptualisation and to guide the analysis, we drew on three complementary 'middle-range' theories often applied in the political economy of nutrition literature: Kingdon's multiple streams theory, ${ }^{20}$ Shiffman and Smith's health priority-setting framework ${ }^{14}$ and Heaver's work on political commitment for nutrition. ${ }^{7}$ These were integrated into an initial theoretical framework (see online supplementary text 1 ).

\section{Search for relevant empirical literature}

To optimise search strings, we undertook preliminary searches of the PubMed, Scopus, ProQuest and Web of Science databases using combinations of terms and database parameters (table 2). These databases were selected for their relevance and comprehensiveness after consultation with two librarians trained in systematic search. A search diary was kept to record progress and modifications to the protocol (see online supplementary text 2). We conducted a search for primary literature between August and October 2016. Acknowledging the large practice-orientated grey literature on the political economy of nutrition, we also searched the websites of international organisations with a mandate to address malnutrition in October 2016 (table 2). To capture studies missed in the initial search, additional searches were conducted in February 2017.

\section{Selecting studies and quality appraisal}

References for all studies were entered into an EndNote library. Studies were selected against the inclusion and 
Table 2 Databases and websites searched, search terms and inclusion/exclusion criteria

\begin{tabular}{|c|c|c|}
\hline Search & Databases/institutional websites & Search terms \\
\hline $\begin{array}{l}\text { Scholarly } \\
\text { literature }\end{array}$ & PubMed, Scopus, ProQuest, Web of Science & \multirow{2}{*}{$\begin{array}{l}\text { Nutrition-related: } \text { diet }^{*}, \text { food }^{\star} \text {, hunger, } \\
\text { micronutrient deficienc*, nourish*, "nutrition*, } \\
\text { obesity, overweight, stunting, underweight, } \\
\text { wasting } \\
\text { Political commitment related: accountabilit*, } \\
\text { advoca*, agenda*, capacit*, collective action, }_{\text {commit*, coordination, enabling environment*, }} \text {, } \\
\text { govern*, politic*, policy, policies, priorit*, } \\
\text { stewardship, strateg* }\end{array}$} \\
\hline Grey literature & $\begin{array}{l}\text { Eldis; Food and Agriculture Organization of the United } \\
\text { Nations; Institute for Development Studies; International } \\
\text { Food Policy Research Institute; International Fund for } \\
\text { Agricultural Development; Oxfam International; Save the } \\
\text { Children; Scaling-up Nutrition; United Nations Children's } \\
\text { Fund; United Nations Standing Committee on Nutrition; } \\
\text { World Bank; World Food Programme; World Health } \\
\text { Organization. }\end{array}$ & \\
\hline
\end{tabular}

Studies were 1. Published after 1990 in English.

included if: $\quad 2$. Published in a peer-reviewed journal or by an official organisation or non-government organisation with a mandate to address malnutrition.

3. Identified and described factors shaping political commitment for nutrition at national and/or subnational levels.

4. Involved an empirical analysis with clearly described aims, explicit use of theory or description of underlying assumptions, a clear study design and methodology including data sources, coherent statement of findings and justifiable conclusions.

Studies were 1. Non-empirical (eg, commentaries, conceptual frameworks, calls to action).

excluded if: $\quad$ 2. Focused on specific institutional (eg, school, prisons and workplaces) or clinical policy-settings (ie, not at jurisdictional level).

${ }^{\star}$ Truncated to capture all variations of the word (eg, "nutrition* captures malnutrition, overnutrition and undernutrition).

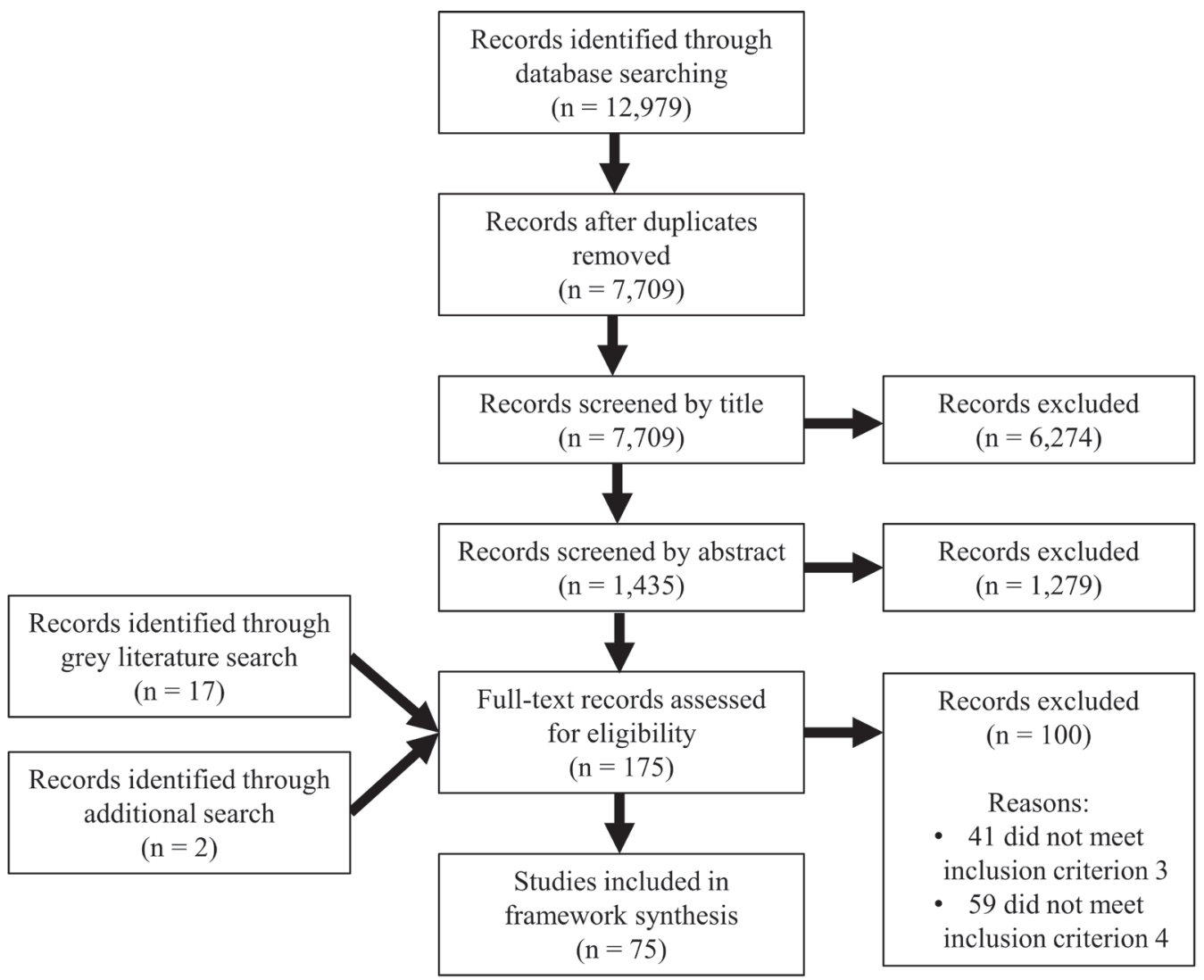

Figure 1 The search process. 
exclusion criteria in table 2 . Study quality was appraised by relevance to the review aim (inclusion criterion 3 ) and robustness (inclusion criterion 4). A diagram of the search process is given in figure 1 . To check for interassessor reliability, PB and KW independently screened a sample of records by title, abstract and full text (see online supplementary text 2). The final list of included articles was approved by all authors.

\section{Data extraction, analysis and synthesis}

Data were extracted in two steps. First, PB read all full texts and extracted the following basic data into an Excel (Microsoft) spreadsheet: study characteristics (authors, year, title, aims/objectives, policy focus, theory used, study design, methods, data sources, funding source); setting (focal nutrition issue, geographical level, jurisdiction name, income-level); outcomes (study conclusions/ key findings, commitment outcome). Second, studies were coded in ATLAS.ti (Scientific Software GmbH) using a coding schema derived from the initial framework and refined abductively using constant comparative analysis, whereby the coded concepts were confirmed, integrated, modified and/or added to through iterations of data analysis. ${ }^{21}$

Data were then synthesised. First, text associated with each code was read in situ by PB and summarised, including: (i) a definition of each factor, identified as what influenced commitment; (ii) the mechanism(s) associated with it, identified as underlying entities, structures or processes that transmitted a causal force between the factor and political commitment (either stated in the study or inferred) ${ }^{22}$ and (iii) cofactors that amplified, diminished and/or sustained the mechanism. On this basis, we defined 'context' as 'underlying social, economic and physical phenomena' influencing how the mechanism functioned to generate an outcome. ${ }^{23}$ Second, any cofactors missed in the first step were identified using the ATLAS.ti code cooccurrence tool.

\section{Populating and modifying the framework}

The synthesised data corresponding to modified or new factors were populated into the thematic categories of the framework to generate the final version. ${ }^{16}$ All authors reviewed iterations of the results and final tables.

\section{RESULTS}

\section{Description of included studies}

A total of 75 studies were included (see online supplementary text 3 ). There was an upsurge in publications per year in the 2006-2017 period, likely reflecting increased attention to nutrition's political economy. By World Bank country income status, studies spanned 31 (38\%) high-income (HICs), 13 (16\%) upper-middle-income (UMICs), 22 (27\%) lower-middle (LMICs) and $15(18 \%)$ low-income (LICs) countries. By issue, $6(8 \%)$ focused on food security, $22(30 \%)$ on general malnutrition, $2(3 \%)$ on micronutrient deficiencies, $28(38 \%)$ on overweight/obesity and diet-related NCDs and 16 (22\%) on undernutrition. Overweight/obesity and diet-related NCDs was the predominant focus in HICs and UMICs studies, and undernutrition in LMICs and LICs. Only one study explicitly focused on the double burden of malnutrition.

By jurisdictional level, 51 (68\%) involved national jurisdictions, 17 (23\%) subnational (region/province/ state) and $4(5 \%)$ subnational (local/municipal). A small number involved multilevel jurisdictions; 2 (3\%) national and subnational (regional) and $1(1 \%)$ national and supranational. Twenty-five frameworks, theories and models were identified across the included studies. Ten (14\%) used the multiple streams theory, $9(12 \%)$ a governance framework, $6(8 \%)$ framing theory, $6(8 \%)$ Shiffman and Smith's framework, 5 (7\%) Clark's policy science framework, $4(5 \%)$ the advocacy coalition framework and $4(5 \%)$ the enabling environments for nutrition framework $(6 \%)$. Twenty-four $(32 \%)$ adopted a theoretically pluralistic approach that integrated two or more theories.

\section{Factors generating, sustaining and constraining political commitment}

As described in table 3 , a total of 18 factors were identified as driving commitment, organised into five themes: actors; institutions; political and societal contexts; knowledge evidence and framing; and, capacities and resources. These were conceptualised as increasing or decreasing the probability of political commitment, rather than in terms of necessity or sufficiency. ${ }^{14}$ A more elaborate representation of these factors is given in online supplementary text 4 , tables S4.1-S4.5. As demonstrated by the cofactors column in these tables, the determinants of commitment identified were dynamic, strongly interdependent and context-dependent.

\section{Actors}

Irrespective of country-context, effective nutrition actor networks (NANs) (factor 1) generated commitment through inter alia advocacy and awareness-raising, framing nutrition problems and solutions (ie, norm promotion), generating data and evidence, coordinating policy development, implementation and monitoring activities, building capacities and mobilising resources. ${ }^{24-47}$ Such networks varied widely in structure (formal vs informal), maturity (nascent vs highly evolved) and membership composition including parliamentarians, bureaucrats, academics, international agencies and civil society representatives. ${ }^{24-47}$ Their effectiveness was enhanced in the context of high cohesion among members, ${ }^{29} 303240-47$ strong leadership ${ }^{44-46}$ and when possessing strategic and organisational capacities. ${ }^{25} 29374348-50$ Conflict and fragmentation within NANs was, however, frequently reported resulting from many topics of disagreement. 1225283334364051

Nutrition leaders (factor 2), including those within and outside of government enabled commitment in many studies through establishing, unifying and mobilising 
Table 3 Factors identified as driving political commitment for nutrition

Category Factor and description

Actors

(1) Nutrition actor network (NAN) effectiveness: effectiveness of NANs, the individuals and organisations operating within a given jurisdiction who shared common principles, causal beliefs and/ or interest in tackling malnutrition and who acted collectively to do so. ${ }^{142025}$

(2) Strength of leadership: presence of committed and politically savvy individuals, within or outside of government, recognised as strong champions for nutrition. ${ }^{7142026}$

(3) Civil society mobilisation: extent to which civil society groups mobilised to address malnutrition, including non-government organisations and social movements collectively representing the interests of citizens. $^{714}$

(4) Supportive international actors: degree to which actors with an international scope of operations and/or membership initiated, championed and/or supported nutrition policy and programming responses. ${ }^{1427}$

(5) Private sector interference: degree to which mobilised private interest groups undermined effective nutrition policy responses, including food producers, retailers, marketers and their representative peak bodies. ${ }^{2874}$

Institutions

(6) Strength of institutions: extent to which coordinating agencies and institutional systems mandated

to address malnutrition were empowered to effectively coordinate multisector/multilevel responses and advocate for sustained attention and resources. ${ }^{7145360}$

(7) Effective vertical coordination: degree to which nutrition policies were effectively coordinated, implemented and monitored across levels of governance, particularly regarding the incentives of subnational actors to adopt, progress and benefit from central government policies. ${ }^{29} 528689$

(8) Legislative, regulatory and policy frameworks: degree to which national nutrition policies, operational plans and enabling legislation were well-designed and enacted, and/or the alignment of nutrition objectives with broader policy agendas and regulatory frameworks. ${ }^{617181}$

Political and societal (9) Supportive political administrations: degree to which members of the executive (eg, head of state, contexts ministers), legislative (eg, parliamentarians) and administrative (eg, agency heads, senior officials) branches of government initiated and championed nutrition responses. ${ }^{12} 3052$

(10) Societal conditions and focusing events: extent to which changing societal conditions (longduration phenomena) or focusing events (short-term processes) focused attention onto nutrition or closely related issues and presented opportunities or impediments to commitment-building. ${ }^{1420273132}$

(11) Ideology and institutional norms: extent to which entrenched belief systems and practices predominant within political systems, policy-making institutions and/or in society-at-large, negatively skewed perceptions about malnutrition problems and undermined effective policy responses. 152025284894

Knowledge, evidence and framing

(12) Credible indicators and data systems: availability of credible indicators and high-quality data systems for monitoring nutrition problems, informing policy design, tracking progress and empowering accountability systems. ${ }^{71415} 5253$

(13) Evidence: extent to which robust evidence on the causes, manifestations and consequences of malnutrition and the efficacy and cost-effectiveness of interventions was available, clearly communicated and accepted. ${ }^{1428} 75$

(14) Internal frame alignment: degree to which NANs were aligned around a common interpretation and narrative of a given malnutrition problem including its definition, magnitude, causes and solutions for resolving it. ${ }^{1425} 272931$

(15) External frame resonance: degree to which NANs publicly portrayed (ie, framed) nutrition problems and solutions in ways that resonated with and motivated action by external audiences, and countered the frames deployed by opponents. ${ }^{142027283152}$

Capacities and resources

(16) Strategic capacities: degree to which NAN members possessed 'soft-power' skills including the capacity to generate consensus, resolve conflicts, respond to recurring opportunities and challenges, build strategic alliances, undertake strategic communications and related tasks. ${ }^{731}$

(17) Organisational capacities: degree to which NAN members possessed the technical knowledge and skills, administrative systems and human resources required to generate commitment, including through the effective management of nutrition policy and programming responses. ${ }^{7152431}$

(18) Financial resources: degree to which nutrition budgetary commitments and financing systems incentivised multisector/multilevel coordination, ensured successful policy implementation and created ownership and entitlements among political elites, policy-makers, citizens and other stakeholders. ${ }^{72}$ 
NANs, championing policy ideas and engaging with decision-makers. ${ }^{15} 242932364144-46$ 52-59 They included advocates promoting external attention to nutrition, policy entrepreneurs (eg, who softened-up technical communities to political realities, built consensus and advocated policy ideas) and high-level political champions. ${ }^{12} 2426274041434446-49$ 54-57 59-64 Their leadership was enhanced when possessing certain strategic capacities (eg, emotional intelligence, management, communication, negotiation and conflict management skills), ${ }^{24} 263136414345465455$ they had the support of highlevel political champions ${ }^{2654} 55$ and when elected or appointed into positions of authority (eg, as legislators or high-level bureaucrats). ${ }^{243641434546535765}$

The mobilisation of civil society groups (factor 3), including a diversity of international and national non-governmental organisations and social movements (eg, health-orientated, disease-specific, faithbased, consumer-focused), was often integral to NAN formation, development and impact. Groups varied in their expertise, available resources and functional roles. ${ }^{26} 27$ 29-32 $454652536266-69$ Their activities included advocacy, awareness-raising and coalition-building, acting as an accountability mechanism (eg, by monitoring and reporting on government and other stakeholder activities), giving voice to the politically marginalised, delivering on-the-ground services and informing policy development, monitoring and calibration. ${ }^{26} 2729-324546525362$ 66-69 Civil society impact was enhanced when supported by the media ${ }^{2755}$ and international actors, ${ }^{29} 5370$ and when inclusive governance arrangements linked policy-makers with civil society groups and policy beneficiaries. ${ }^{30} 42454852536471$

In several LIC and MIC studies, supportive international actors (factor 4) enabled commitment by mobilising resources for policy, programming and capacity-building, ${ }^{29} 485255616372$ providing technical assistance and legitimacy to policy initiatives, ${ }^{12} 26434460$ and by advocating to governments. ${ }^{25} 43444853$ They included multilateral organisations (eg, World Health Organization, Unicef, World Bank), donor agencies (eg, United States Agency for International Development, United Kingdom's Department for International Development) and global nutrition initiatives (eg, Scaling Up Nutrition). ${ }^{15} 3942-44535557616367$ In some cases, policy and programming was almost entirely donordriven. ${ }^{6163} 72$ The role of international actors was weakened when their actions were misaligned with government priorities, ${ }^{24} 253152$ when the absence of coherent government policies, coordinating structures and accountability mechanisms encouraged donors to 'go it alone ', $^{38} 70$ and when recipient governments became overdependent on donor financing. ${ }^{39} 63$

In many MIC and HIC studies, private sector interference (factor 5) impeded commitment for food regulations targeting obesity prevention by inter alia undermining policy debates (eg, by emphasising individual or parental responsibility, disputing evidence, intervention as 'nanny-statist'), pre-emptively adopting self-regulation (ie, policy substitution) and direct lobbying of policy-makers. ${ }^{28} 353673-80$ This was enhanced in the context of a neoliberal ideology $y^{28557381-83}$ including a shift towards hybrid (ie, public-private) governance arrangements that expanded private-interest influence in public policy, ${ }^{28} 3573798284$ the food industry's 'productivist power' as suppliers of jobs and tax revenue 283553 and greater international capital mobility (ie, via trade liberalisation) allowing transnational corporations to punish or reward governments for their policy decisions. ${ }^{56} 79$ In some LIC and MIC studies, agricultural subsidies, tax concessions and 'pork-barrelling' may have created powerful private-interest constituencies resisting nutrition-sensitive agriculture and food distribution policy change. ${ }^{2752617085}$

\section{Institutions}

Tackling malnutrition requires coordinated action and commitment within and across multiple sectors (horizontal coordination) and levels (vertical coordination) of governance. The complex institutional arrangements involved, the absence of institutional ownership for nutrition, and institutional failure often impeded this. ${ }^{1524262740454852606167}$ The establishment of empowered coordinating agencies and institutional systems with a mandate to address malnutrition (factor 6) was important in overcoming these challenges through inter alia providing structures for convening stakeholders, coordinating multisector/multilevel policy development, implementation and monitoring activities and mobilising human, technical and financial resources. ${ }^{252730404344525560}$ This often centrally involved the health and agricultural sectors, but also inter alia education, gender, labour, finance, economic development, industry, water and sanitation, social protection and trade. ${ }^{24} 3044505259-61676986-88$

Coordinating agencies were typically located within suprasectoral agencies (eg, office of the prime minister) or line agencies (eg, ministry of health, agriculture), ${ }^{27434453}$ and embedded within wider multisector/ multilevel institutional systems with delineated roles and responsibilities. ${ }^{2430434553}$ Agencies were more often effective when positioned suprasectorally and possessing sufficient capacities, resources and leadership, ${ }^{12} 2453556769$ and when institutional systems had strong multisector/ multilevel cooperation incentives (eg, enabling legislation, policies and plans, shared and sector-specific goals, performance measures and performance and/or resultsbased budgeting systems). ${ }^{4353616771}$ Institutional failure resulted from inter alia insufficient authority, capacities and resources (often when located within politically weak line ministries), ${ }^{27} 39435253616970$ an overfocus on technical or implementation activities to the neglect of advocacy $^{245360}$ and interorganisational competition. ${ }^{24} 3960$

Vertical coordination presented a significant challenge given the many actors involved in policy and programming activities within and across levels of governance. $^{12} 2425282939526163697276868990$ Effective vertical coordination (factor 7) was important for incentivising 
actions, building ownership and driving coordinated action along national to subnational implementation pathways'. ${ }^{29} 525363718689$ This was enhanced through strong cooperation incentives (eg, legislation requiring multilevel cooperation, resource transfers and performance and/or results-based budgeting), , $^{53} 71$ and subnational institutional structures with sufficient capacities and resources. ${ }^{29} 525363$ Decentralisation processes underway in many countries increased the power of subnational stakeholders, making their involvement in centralised policy processes critical, ${ }^{254952536063}$ and their exclusion detrimental. ${ }^{38} 52616367$ In some cases, decentralisation also undermined the authority of centralised coordinating agencies. ${ }^{25} 3943496063$

The development and adoption of national nutrition policies, operational plans and enabling legislation (factor 8) enabled commitment by demonstrating commitments to which governments could be held accountable, enabling beliefs on the need for coordinated action within government, and by providing a framework for action. ${ }^{15} 46536163676971$ Commitment was further enhanced when nutrition was positioned within broader national development plans, social welfare reforms and/or poverty reduction strategies, ${ }^{24} 2945535666$ when global-level policies and/or commitments compelled national governments to initiate responses 424352576391 and when policies had clear numerical commitments that enhanced accountability. ${ }^{52} 6192$ It was diminished when nutrition was excluded or marginalised from broader policy agendas, ${ }^{606193}$ and when there was limited capacity to achieve consensus among stakeholders during policy processes. 15313764

\section{Political and societal contexts}

Political administrations, including the executive, legislative and administrative branches of government were often the primary power structures shaping nutrition responses at all levels. Supportive political administrations (factor 9) enabled commitment by articulating policy debates, championing policy initiatives, facilitating inclusive policy processes (eg, public consultations), drafting policy and legislation, providing institutional memory and enhancing accountability through oversight of policy initiatives, agencies and expenditures. ${ }^{12} 29304552$ This was more likely with the election or electoral continuity of governments with strong social welfare and antipoverty agendas, ${ }^{12} 24273842455253555671$ when actions were taken to build non-partisan (ie, multiparty or multifaction) coalitions for nutrition and when parliamentarians were actively involved in policy processes. ${ }^{30} 4352$

Unsupportive political administrations were frequently reported. ${ }^{25} 293845525561698393$ In several cases, rhetorical commitments by members of the executive branch were not converted into directives for legislative and administrative enactment. ${ }^{1524525370}$ This was more likely in the context of weak electoral demand and/or civil society pressure (ie, reducing the political costs of inaction), ${ }^{2538455255616993}$ the low-level visibility of nutrition and poor nutritional literacy among parliamentarians, administrators and citizens, ${ }^{15} 3839496366$ when attention to nutrition was eclipsed by more tangible 'vote-winning' issues $^{24} 384042434960616367$ and in highly partisan, fragmented or unstable political environments. ${ }^{38}$ In some HIC studies, commitment for food regulations targeting obesity prevention was undermined by the election of, or congressional control by, more right-wing (eg, liberal-conservative) governments. ${ }^{28} 353658$

Long-term changes in societal conditions and shortterm focusing events (factor 11) presented opportunities or challenges for generating commitment by influencing many aspects of government policy agendas and by focusing public and political attention directly onto or away from nutrition and/or closely related issues. 27313264 Examples of these are given in table 4. Some focusing events (eg, famines) were detrimental when they focused attention onto and institutionalised food production and distribution responses at the expense of broader (ie, nutrition-sensitive) and longer-term responses to undernutrition. ${ }^{31}$ Changing societal conditions and focusing events were more likely to advance commitment when NANs had sufficient foresight, leadership and capacities to take advantage of emerging opportunities or mitigate threats. ${ }^{3164}$

Certain belief systems (factor 12) entrenched within political systems, policy-making institutions and/or in society-at-large were found to narrow or skew perceptions about the scale, scope and nature of nutrition problems, thereby impeding commitment for more balanced policy responses addressing the wider determinants of malnutrition. ${ }^{152528} 488294$ Three were most evident as described in table 5. In primarily HIC studies, a 'neoliberal ideology' was found to skew overweight/obesity responses towards behavioural-lifestyle and market-driven (ie, industry-led) approaches with a limited role for government and legislative intervention. ${ }^{28} 32355673$ 81-83 $\mathrm{In}$ several LIC and MICs, a 'food-centric' belief system was found to orientate policy responses towards agricultural production, food distribution and hunger reduction to the exclusion of nutrition. ${ }^{131527314953556163686993}$ A 'nutricentric' belief system skewed undernutrition responses towards nutrition-specific and/or curative/biomedical interventions to the neglect of nutrition-sensitive ones. ${ }^{384452536163}$

\section{Knowledge, evidence and framing}

Irrespective of issue or country-context, the availability of credible indicators and data systems (factor 12) was critical to enabling commitment by informing problem identification (ie, demonstrating the changing prevalence and distribution of malnutrition), policy development, monitoring and calibration activities, the development of internal frame alignment (ie, a shared discourse) within NANs, and as a foundation for effective financing and accountability systems. ${ }^{121526-3140434452-5557596668757690}$ Data demonstrating 'policy success' enabled successful advocacy efforts for sustaining long-term commitment. ${ }^{2440444990}$ Insufficient data and weak data systems were, however, 
Table 4 Changing societal conditions and focusing events as commitment-building opportunities or challenges

Type Identified examples presenting opportunities $(\uparrow)$ or challenges $(\downarrow)$

Societal conditions: Long-duration $\uparrow$ Long-term trends in population health, food systems change and nutrition status (eg, phenomena that influenced many aspects of government policy agendas that were directly or indirectly related to nutrition. ${ }^{31} 32$ epidemiological transition, nutrition transition) ${ }^{283757} ; \uparrow$ transition to democracy enabling more socially orientated policies ${ }^{4566}$; $\uparrow$ economic growth enabling greater resources for nutrition budgetary commitments. ${ }^{27} 55 \downarrow$ Sustained conflict/insecurity $3947091100 ; \downarrow$ weak government revenue-raising capacity constraining nutrition budgetary commitments ${ }^{27} 52586870$; $\downarrow$ widespread corruption and embezzlement ${ }^{27} 5268 ; \downarrow$ economic downturn/austerity reducing support for food regulations targeting obesity prevention due to perceived costs/impacts on food industry. ${ }^{28} 323458$

Focusing events: short-duration processes that focused $\uparrow$ Famines, natural disasters, political upheavals and economic crises ${ }^{15} 313955636491$; $\uparrow$ highprofile and/or consistent media coverage 1227364155636869737584 ; $\uparrow \downarrow$ political developments attention directly onto nutrition including changes within the executive, legislative and/or administrative branches of or indirectly by association with closely related issues. ${ }^{27} 31$ government, government planning cycles, high-level speeches/debates and ratifying international agreements 121420272830565761 ; $\uparrow$ emergence of broader policy discourses that nutrition actors could sensitise (eg, HIV/AIDS, Millennium Development Goal implementation, primary healthcare, poverty reduction) ${ }^{315559}$; $\uparrow$ direct actions of nutrition actors (eg, highprofile events, publishing reports). ${ }^{15} 2743 \downarrow$ Famines, natural disasters, political upheavals, economic downturn and other crises when institutionalising food distribution responses that excluded nutrition. ${ }^{31}$

reported in many studies, 2627313337384060616383848692 often resulting from the limited capacities, resources and incentives of nutrition actors to collect, analyse and disseminate data. ${ }^{40425261697293}$

Evidence demonstrating the causes and consequences of malnutrition and the efficacy and cost-effectiveness of interventions (factor 13) helped to support effective advocacy and policy activities when available, clearly communicated and accepted. ${ }^{30} 3243444753626671$ This was more likely when evidence was communicated via 'knowledge-brokers',264256 6995 in language policy-makers understand, ${ }^{61} 6995$ by using communicative devices (eg,

Table 5 Prominent belief systems skewing nutrition responses and undermining commitment

\section{Belief system}

Neoliberalism: an ideology emphasising market freedom, minimal government intervention, devolved governance including 'self-governance' by the individual and an expanded role for market actors in all spheres of political, economic and social activity. ${ }^{73} 82$

Nutricentrism: a curative, biomedical or nutrient-centric view of nutrition emphasising nutrition-specific or reductionist interventions to the neglect of integrated, preventative or nutritionsensitive ones. ${ }^{3844525361}$

Food-centrism: the conflation of 'malnutrition with lack of food'. ${ }^{31}$ p\$62 Also described as the 'conflation of food security with nutrition security' or the conflation of a 'commitment to fight hunger with combatting undernutrition'. ${ }^{13 p 280}$

\section{Reinforcing or associated factors}

Behavioural-lifestyle approaches to nutrition that download responsibility onto individuals or parents rather than powerful governments and/or food industry actors $^{28} 3235567382$; an expanded role for the private sector in policy and governance 28357382 ; belief that government should have no or only a minimal role in regulating free markets and enterprise 2835738183 ; deregulation agendas within government including regulatory impact assessments (ie, assessing new regulatory proposals for costs to business) with stringent evidential requirements. ${ }^{8081}$

Placement of nutrition within ministries of health resulting in an overemphasis on nutrition-specific programming 3844526163 ; prevailing narratives at international level (ie, nutrition faddism) narrowing the scope of national nutrition responses (eg, overemphasis on micronutrients) ${ }^{31}$; civil society groups becoming fixated on single issues and presenting ideological resistant to alternatives ${ }^{27}{ }^{38}$; generally, an overly technical or reductionist approach to nutrition disconnected from the messiness of real decision-making, particularly when nutrition actors failed to manage conflicts arising from divergent values, perspectives or interests of a nontechnical nature. ${ }^{12} 242737$

Focusing events (eg, drought, famine, economic crises) that stimulated and institutionalised food distribution and emergency food responses at the expense of long-term development nutrition ${ }^{265261}$; when food distribution and/or food pricing was an entrenched political issue (ie, when perceived as a 'vote-winner' or food insecurity as driving political instability), and when food distribution schemes were highly institutionalised and resistant to change (ie, path dependent) 273138394570 ; when food systems were orientated towards the production and distribution of single commodities (eg, rice in Bangladesh, maize in Zambia) thus creating powerful electoral constituencies resisting nutrition-sensitive policy change ${ }^{526170}$; overemphasis on agricultural commercialisation, cash-cropping and/or export markets (ie, productivism) to the neglect of local social considerations and nutritional needs. ${ }^{61} 89$ 
country profiles, short briefs, nutrition maps $)^{53} 69$ and when authoritative bodies were commissioned to gather, integrate and report evidence. ${ }^{3347} 71$ The perception that evidence was lacking, inconsistent or unconvincing was frequently reported. ${ }^{12} 272833374056616369757680818495$ Although in some studies a strong international evidencebase supported country-level activities, ${ }^{26} \quad 33 \quad 40424366$ many reported an absence of locally relevant evidence and/or the perception that international/national evidence was inapplicable to national/subnational contexts. ${ }^{26} 273133374063838486$ Higher evidential requirements were needed to inform policy decisions when issues were strongly contested, as in the case of food regulations targeting obesity prevention. ${ }^{28} 357584$

NANs that were unified around a common problem definition, causal interpretation and set of proposed solutions (factor 14) were more likely to overcome ideological differences, appease powerful 'veto players' and undertake effective collective action. ${ }^{15}$ 25 29-31 40434655596971 This was more likely when NANs had established structures (eg, governance bodies, conferences, workshops, informal networking events) for sharing information, recruiting and socialising new members, building consensus and managing conflicts, ${ }^{25} 29374348-50525571$ leadership, ${ }^{374452}$ strategic capacities (ie, soft skills) for building consensus and managing conflicts ${ }^{31374044}$ and credible data, evidence and/or a shared causal framework (eg, Unicef nutrition framework) to support a unifying discourse. ${ }^{374452}$ The failure to achieve this 'internal frame alignment' was reported in many cases ${ }^{12} 272836-394449535661687083-8596$ and resulted more often from normative conflicts (eg, divergent interests, organisational mandates, administrative systems or professional cultures) rather than technical ones. ${ }^{24} 252731374964$ Although there were many topics of disagreement within NANs, ${ }^{31} 3752$ distrust and disagreement regarding the private sector's role in nutrition policy was most common. ${ }^{12} 26273237407896$

Certain public portrayals (ie, frames) used by nutrition actors to attribute causality, responsibility, severity, tractability and benefit to an issue were found to resonate strongly with external audiences and thus enable commitment. ${ }^{14} 202886$ Common frames identified are described in table 6. This 'external frame resonance' (factor 14) was more likely when messages were aligned with the underlying values and beliefs of policy decision-makers ${ }^{7} 28434877$ including their perceptions of technical and political feasibility, ${ }^{112} 2448$ when NANs argued behind closed doors and spoke with a common voice $^{314352}$ and when messages were strategically tailored to align with the priorities, interests and needs of target audiences. ${ }^{750778395}$ 'Hooking' nutrition onto high priority non-nutrition issues (ie, frame expansion) was also found to successfully enable "nutrition success without nutrition commitment' by sensitising broader policy agendas (eg, national development agendas, poverty reduction initiatives, school feeding programmes) to nutrition objectives. ${ }^{30} 3149525359$

\section{Capacities and resources}

NANs possessing strategic capacities (factor 16), described as 'a body of craft knowledge with considerable practical utility' ${ }^{31}$ pS63 were more capable of building cohesive NANs, responding to opportunities and countering threats, and managing complex political and policy processes. ${ }^{15243143444647555790}$ At the individual level, this included certain attributes of nutrition leaders (see factor 2) and at the institutional level the capacity for building consensus, managing conflicts and developing competencies, ${ }^{25} 293137434448-50$ establishing and maintaining strategic multistakeholder partnerships (ie, coalition-building) $)^{4044648525362}$ and undertaking strategic communication. The latter included the capacity to negotiate, compromise and tailor messages to different audiences, ${ }^{7} 24313648525557$ advocate for incremental/ realistic changes aligned with decision-maker priorities $^{25} 304349537783$ and to use champions with direct access to policy-makers. ${ }^{41} 43464952$ In several studies, weak strategic capacities were reported as problematic. ${ }^{122427283661}$

Limited organisational capacities (factor 17) frequently undermined commitment by constraining

Table 6 Frames identified in the literature

Type

Frames generating attention and/ or enabling commitment

obesity)

\section{Identified examples}

An economic rationale for intervention including costs to national health systems, economic development and productivity 2861638196 ; vulnerability of children to malnutrition 27287177 ; the human right to food and health ${ }^{12} 27455255$; international comparisons highlighting the particular severity of malnutrition in a country ${ }^{12}$; food industry demonization $^{28}$; increasing use of an obesogenic environment frame locating responsibility with the 'causes of the causes' of obesity and thus with a wider diversity of actors beyond the individual ${ }^{287173}$; when societal conditions and focusing events (eg, drought, HIV/AIDS, health system reforms) provided an opportunity for strategically sensitising broader policy discourses to nutrition. ${ }^{3}$

Oppositional frames (overweight/ Emphasis on individual/parental responsibility over governmental and industry responsibility, portraying scientific evidence as contested or inconclusive 28747579 ; the 'singling-out' of processed foods or beverages for intervention as unfair ${ }^{28327796}$; food regulation as undermining commercial viability ${ }^{283256}$; government as a 'nanny' when intervening to address obesogenic food environments. ${ }^{28} 35737794$ 
the effective management of nutrition policy responses and increasing the likelihood of policy failure (thus trapping nutrition within a low-priority cycle). This was most evident in cases where competent nutrition professionals and administrative staff were lacking, especially at the local level, ${ }^{24} 40424346526163677072869193$ when there was a high turnover of ministers or administrative staff and/or disruptive administrative restructuring, ${ }^{12442446169}$ limited technical capacities particularly for multisectoral/multilevel data collection, management and analysis, ${ }^{40425261697293}$ when high administrative loads were placed on weak coordinating agencies and other relevant institutions 3848525563687072 and when absent or weak budgeting, record-keeping and accounting capacities undermined financial planning, programming efficiency and accountability. ${ }^{48} 5263687072$

The expansion of nutrition budgetary commitments and effective financing systems (factor 18) enabled commitment by empowering coordinating agencies and institutional systems, enabling effective policy implementation, and by creating entitlements among parliamentarians, bureaucrats and citizens. ${ }^{27} 5253666771$ Performance and/or results-based budgeting was effective at incentivising multisector/multilevel cooperation, improving the transparency and accountability of institutional systems and enhancing the efficiency of programming activities. ${ }^{27} 29525366$ More generally, accountability was enhanced when there were transparent financing and accounting systems for tracking disbursements. ${ }^{38} 4852617293$ In many cases, inadequate financial resources or the failure to effectively use existing resources led to poor implementation outcomes and policy failure. ${ }^{2438-40} 434648495261-6367687072909193$ Financing activities were undermined by a limited capacity of subnational implementation partners to use or reciprocate funding from central government, ${ }^{12} 5262$ the absence of nutrition line items in government budgets or the nesting of nutrition within budgets for non-mandated departments or issues ${ }^{636772}$ and when siloed financing arrangements encouraged interagency competition and disincentivised cooperation. ${ }^{24} 3840486093$

\section{DISCUSSION}

We used a theoretically driven review method to identify the determinants of political commitment for nutrition at the country-level. Overall, we identified and described 18 factors organised into five themes: actors; institutions; political and societal contexts; knowledge, evidence and framing; and, capacities and resources. Many of the identified factors have been described previously in the literature on nutrition's political economy' The results affirm the findings of reviews on undernutrition in low-income and middle-income countries, ${ }^{8912}$ and on nutrition and obesity in middle-income and high-income countries. ${ }^{1197}$ Similar themes have been found in global and supranational studies. ${ }^{88} 98$ We have, however, extended this work in two notable ways.
First, we integrated the nutrition politics and policy literature relevant to 'malnutrition in all its forms', thus spanning all issues and country-contexts. Although the included studies were not always directly comparable (due to differences in study design, theoretical focus and methods used), many of the determinants of political commitment were similar across issues and contexts. Irrespectively, effective nutrition actor networks, strong leadership, civil society mobilisation, supportive political administrations, changing societal conditions and focusing events, cohesive and resonant framing, and data systems and evidence were commitment drivers.

There were some notable exceptions, likely reflecting the focus of distinct bodies of researchers working in different country-contexts. For example, factors within the 'institutions' and 'capacities and resources' themes were almost exclusively reported in low-income and middle-income country studies, although these are very likely to be important in high-income countries. Private sector interference was reported as impeding policy responses to obesity and diet-related NCDs exclusively in upper-middle-income and high-income countries. Nonetheless, these findings suggest that addressing malnutrition in all its forms is likely to require some core types of commitment-building activities, but with some context-dependent adaptations.

Second, previous reviews have listed and described relevant factors but have neither elaborated on their interactions nor elaborated significantly on the role of context. Our results demonstrate that the determinants of political commitment for nutrition are strongly interdependent, context-dependent and dynamic, thus demonstrating systems-like features. This supports the need and provides a foundation for understanding the drivers of political commitment, and arguably the political economy of nutrition more generally, within a non-linear and dynamic model of change. ${ }^{52}$ Qualitative system-dynamics modelling could be used to generate such a model and elaborate on the functioning of 'food and nutrition political economy systems'. In this perspective, the effects of interactions among factors are likely to be significantly greater than the sum of their individual effects in isolation. ${ }^{99}$

\section{Future research directions}

Although in recent decades a rich and growing literature on the political economy of nutrition has emerged, many evidence gaps remain. In this section we explore a number of these.

Theoretically, the broad repertoire of frameworks, theories and models used across the literature has provided multiple lenses through which to understand this complex topic. Arguably, studies using comprehensive and theoretically pluralistic frameworks ${ }^{152038}$ have generated deeper insights into the functioning of food and nutrition political economy systems as a whole, than those focused on certain facets (eg, framing) or policy process stages (eg, agenda-setting). Overall, we found 
the theory-driven framework synthesis method well suited to our aim of understanding a complex political phenomenon. However, empirical evidence in theoretically guided research is always generated, at least to some extent, by the theory itself. Thus, we may have missed important drivers of political commitment because they have been undertheorised and thus under-reported in the literature. Indeed, important approaches in political science (eg, new institutionalism) are largely absent and provide avenues for guiding future investigation.

Substantively, there are many research questions in need of answers of which some-given their cross-cutting nature-are arguably most important. Several concern nutrition actor networks. How do such networks form, evolve and become effective? What pragmatic actions can be taken to rapidly enhance their effectiveness within countries? Several institutionalised belief systems (eg, food-bias, nutricentrism) are strong commitment barriers. Why have these become institutionalised in some jurisdictions but not others? How might these be countered? Very few studies have focused on the reality that NANs concerned with obesity tend to be different to those concerned with undernutrition. What opportunities does bringing together people and entities concerned with different forms of malnutrition present for furthering commitment to nutrition, especially as new institutional systems and policies for tackling overweight/obesity and diet-related NCDs are layered onto existing ones for undernutrition? The role of parliamentarians is also underexplored. ${ }^{52}$ How can non-partisan support for nutrition be attained and sustained more systematically at this level? Private sector interference is reported to have strongly impeded commitment for overweight/obesity and diet-related NCD prevention. How can NANs more effectively counteract this interference, while recognising that the private sector will inevitably have to be involved in delivering on objectives?

\section{CONCLUSION}

In this review we asked: what factors generate, sustain and constrain political commitment for nutrition at national and subnational levels, how and under what circumstances? Our aim was to inform strategic actions for building commitment over the United Nations Decade of Action on Nutrition. Overall, 18 factors were identified organised into five themes: actors; institutions; political and societal contexts; knowledge, evidence and framing; and, capacities and resources. The results demonstrate that the processes driving commitment are multifactorial, dynamic and strongly context-dependent. Furthermore, commitment is not something that simply exists or emerges accidentally; it can be created and strengthened over time through strategic action. ${ }^{9}$

Many of the divers of political commitment are similar irrespective of country-context or nutrition issue, but with some notable exceptions. This suggests that effective commitment-building strategies are likely to involve a set of core actions but with some context-dependent adaptations. The main core action identified through this study is sustained commitment-building actions by cohesive, responsive and strongly led nutrition actor networks. Accelerating the development of such networks should be a core task for all actors involved, including international development partners. To achieve their goals, nutrition actor networks should aim to enrol the support of political leaders, parliamentarians and administrative elites and mobilise civil society coalitions. To sustain commitment, they must establish empowered institutions, develop organisational and strategic capacities, generate commitment among implementation partners at all levels and mobilise the financial resources to do so.

\section{Author affiliations}

${ }^{1}$ Institute for Physical Activity and Nutrition, School of Exercise and Nutrition Sciences, Deakin University, Geelong, Victoria, Australia

${ }^{2}$ Centre for Food Policy, City University London, London, UK

${ }^{3}$ Department of Nutrition for Health and Development, World Health Organisation, Geneva, Switzerland

${ }^{4}$ Department of Health Policy, London School of Economics and Political Science, London, UK

${ }^{5}$ Menzies Centre for Health Policy, University of Sydney, Sydney, New South Wales, Australia

${ }^{6}$ Faculty of Public Health and Policy, London School of Hygiene and Tropical Medicine, London, UK

${ }^{7}$ Leverhulme Centre for Integrated Research on Agriculture and Health, London, UK

Contributors $\mathrm{PB}, \mathrm{CH}$ and $\mathrm{ARD}$ proposed the idea for the review. PB developed the review protocol with input from all authors. $\mathrm{PB}$ and $\mathrm{KW}$ undertook the systematic search with final approval of included studies by all authors. PB extracted the data including coding of the included studies, analysed the data with input from $\mathrm{KW}$ and wrote the first draft of the manuscript. All authors provided input into the interpretations of the results and ongoing iterations of the manuscript. All authors approved the final version.

Funding Funding for the development of this paper was provided by the Department of Nutrition for Health and Development, WHO, Switzerland.

Disclaimer The authors alone are responsible for the views expressed in this publication and they do not necessarily represent the decisions, policy or views of the WHO.

Competing interests ARD is a full-time staff member of WHO.

Provenance and peer review Not commissioned; externally peer reviewed.

Data sharing statement We have provided all data as supplemental text.

Open Access This is an Open Access article distributed in accordance with the Creative Commons Attribution Non Commercial (CC BY-NC 4.0) license, which permits others to distribute, remix, adapt, build upon this work non-commercially, and license their derivative works on different terms, provided the original work is properly cited and the use is non-commercial. See: http://creativecommons.org/ licenses/by-nc/4.0/

(C) Article author(s) (or their employer(s) unless otherwise stated in the text of the article) 2018. All rights reserved. No commercial use is permitted unless otherwise expressly granted.

\section{REFERENCES}

1. Food and Agriculture Organization of the United Nations. State of food insecurity in the world 2015. Rome, Italy: Food and Agriculture Organization of the United Nations, 2015.

2. NCD Risk Factor Collaboration (NCD-RisC). Trends in adult bodymass index in 200 countries from 1975 to 2014: a pooled analysis of 1698 population-based measurement studies with $19 \cdot 2$ million participants. Lancet 2016;387:1377-96.

3. United Nations Children's Fund, World Health Organization, World Bank Group. Levels and trends in child malnutrition: UNICEF 
/ WHO / World Bank Group joint child malnutrition estimates. Geneva, Switzerland: United Nations Children's Fund, World Health Organization, World Bank Group, 2017.

4. International Food Policy Research Institute. Global nutrition report. Washington, DC: International Food Policy Research Institute, 2017

5. World Health Organization. The double burden of malnutrition: policy brief. Geneva, Switzerland: World Health Organization, 2017.

6. Food and Agricultural Organization of the United Nations, World Health organization. Second international conference on nutrition, conference outcome document: framework for action. Rome, Italy: Food and Agricultural Organization of the United Nations, World Health organization, 2014

7. Heaver R. Strengthening country commitment to human development: lessons from nutrition. Washington, DC: World Bank, 2005

8. Nisbett N, Gillespie S, Haddad L, et al. Why Worry About the Politics of Childhood Undernutrition? World Dev 2014;64:420-33.

9. Gillespie S, Haddad L, Mannar V, et al. The politics of reducing malnutrition: building commitment and accelerating progress. Lancet 2013;382:552-69.

10. World Health Organization. Global nutrition policy review: what does it take to scale up nutrition action? Geneva, Switzerland 2013.

11. Cullerton K, Donnet T, Lee A, et al. Using political science to progress public health nutrition: a systematic review. Public Health Nutr 2016;19:2070-8.

12. Reich M, Balarajan Y. Political economy analysis for food and nutrition security. Washington, DC: World Bank, 2012.

13. te Lintelo DJH, Lakshman RWD. Equate and Conflate: Political Commitment to Hunger and Undernutrition Reduction in Five HighBurden Countries. World Dev 2015;76:280-92.

14. Shiffman J, Smith S. Generation of political priority for global health initiatives: a framework and case study of maternal mortality. Lancet 2007;370:1370-9.

15. Pelletier DL, Frongillo EA, Gervais S, et al. Nutrition agenda setting, policy formulation and implementation: lessons from the mainstreaming nutrition initiative. Health Policy Plan 2012;27:19-31.

16. Ritchie J, Spencer L. Qualitative data analysis for applied policy research. In: Bryman A, Burgess R, eds. Analysing qualitative data. London, UK: Routledge, 2013:173-94.

17. Barnett-Page E, Thomas J. Methods for the synthesis of qualitative research: a critical review. BMC Med Res Methodol 2009;9:59.

18. Pawson R, Greenhalgh T, Harvey G, et al. Realist reviewa new method of systematic review designed for complex policy interventions. J Health Serv Res Policy 2005;10(Suppl 1):21-34.

19. Wong G, Greenhalgh T, Westhorp G, et al. RAMESES publication standards: realist syntheses. BMC Med 2013;11:21.

20. Kingdon JW. Agendas, alternatives, and public policies. London, UK: Harper Collins, 1995.

21. Corbin J, Strauss A. Basics of qualitative research: techniques and procedures for developing grounded theory. Thousand Oaks, CA: SAGE Research Methods, 2008

22. Dalkin SM, Greenhalgh J, Jones D, et al. Whats in a mechanism? Development of a key concept in realist evaluation. Implement Sci 2015;10:49

23. George AL, Bennett A. Case studies and theory development in the social sciences. Cambridge, MA: MIT Press, 2005.

24. Hoey L, Pelletier DL. Bolivia's multisectoral zero malnutrition program: insights on commitment, collaboration, and capacities. Food Nutr Bull 2011;32(Suppl):S70-81.

25. Pelletier D, Pelto G. From efficacy research to large-scale impact on undernutrition: the role of organizational cultures. Adv Nutr 2013;4:687-96.

26. Nisbett N, Wach E, Haddad L, et al. What drives and constrains effective leadership in tackling child undernutrition? Findings from Bangladesh, Ethiopia, India and Kenya. Food Policy 2015;53:33-45.

27. Balarajan Y, Reich MR. Political economy of child nutrition policy: a qualitative study of India's Integrated Child Development Services (ICDS) scheme. Food Policy 2016;62:88-98.

28. Baker P, Gill T, Friel S, et al. Generating political priority for regulatory interventions targeting obesity prevention: an Australian case study. Soc Sci Med2017;177:141-9.

29. Mejía Acosta A, Haddad L. The politics of success in the fight against malnutrition in Peru. Food Policy 2014;44:26-35.

30. Hawkes C, Brazil BG, Castro IR, et al. How to engage across sectors: lessons from agriculture and nutrition in the Brazilian School Feeding Program. Rev Saude Publica 2016;50:38.

31. Pelletier DL, Menon P, Ngo T, et al. The nutrition policy process: the role of strategic capacity in advancing national nutrition agendas. Food Nutr Bull 2011;32(Suppl):S59-69.
32. Johnson DB, Payne EC, McNeese MA, et al. Menu-labeling policy in King County, Washington. Am J Prev Med 2012;43:S130-35.

33. Colón-Ramos U, Lindsay AC, Monge-Rojas R, et al. Translating research into action: a case study on trans fatty acid research and nutrition policy in Costa Rica. Health Policy Plan 2007;22:363-74.

34. Dinour LM. Conflict and compromise in public health policy: analysis of changes made to five competitive food legislative proposals prior to adoption. Health Educ Behav 2015;42:76-86.

35. Field P, Gauld R. How do vested interests maintain outdated policy? The case of food marketing to New Zealand children. Open Health Serv Policy 2011:4:30-8.

36. Hobbs SH, Ricketts TC, Dodds JM, et al. Analysis of interest group influence on federal school meals regulations 1992 to 1996. J Nutr Educ Behav 2004;36:90-8.

37. Hoey L, Pelletier DL. The management of conflict in nutrition policy formulation: choosing growth-monitoring indicators in the context of dual burden. Food Nutr Bull 2011;32(Suppl):S82-91.

38. Taylor L. Analysing nutrition governance: Bangladesh country report. Brighton, UK: Institute of Development Studies, 2012.

39. Zaidi S, Mohmand SK, Hayat N, et al. Nutrition policy in the post-devolution context in Pakistan: an analysis of provincial opportunities and barriers*. IDS Bull 2013;44:86-93.

40. Balarajan Y. Creating political priority for micronutrient deficiencies: a qualitative case study from Senegal. BMJ Open 2014;4:e004784.

41. Dodson EA, Fleming C, Boehmer TK, et al. Preventing childhood obesity through state policy: qualitative assessment of enablers and barriers. J Public Health Policy 2009;30(Suppl 1):S161-76.

42. Jeruszka-Bielak M, Sicińska E, Wit Lde, et al. Stakeholders' views on factors influencing nutrition policy: a qualitative study across ten European countries. Polish Journal of Food and Nutrition Sciences 2015;65:293-302.

43. Lapping K, Frongillo EA, Studdert LJ, et al. Prospective analysis of the development of the national nutrition agenda in Vietnam from 2006 to 2008. Health Policy Plan 2012;27:32-41.

44. Levitt EJ, Pelletier DL, Dufour C, et al. Harmonizing agriculture and health sector actions to improve household nutrition: policy experiences from Afghanistan (2002-2007). Food Secur 2011;3:363-81.

45. Mejia-Costa A. Examining the political, institutional and governance aspects of delivering a national multi-sectoral response to reduce maternal and child malnutrition. Brighton, UK: Institute of Development Studies, 2011.

46. Vogel EM, Burt SD, Church J. Case study on nutrition labelling policy-making in Canada. Can J Diet Pract Res 2010;71:85-92.

47. Wegener J, Hanning RM, Raine KD. Generating change: multisectoral perspectives of key facilitators and barriers to food system policy making. J Hunger Environ Nutr 2012;7:137-48.

48. Natalicchio M, Garrett J, Mulder-Sibanda M, et al. Carrots and sticks: the political economy of nutrition policy reforms. Washington, DC: World Bank, 2009.

49. Hajeebhoy N, Rigsby A, Mccoll A, et al. Change strategies to protect, promote, and support infant and young child feeding. Nutr Bull 2013;34(Suppl):S181-94.

50. Clayton ML, Frattaroli S, Palmer A, et al. The role of partnerships in U.S. food policy council policy activities. PLoS One 2015;10:e0122870.

51. Fox AM, Balarajan Y, Cheng C, et al. Measuring political commitment and opportunities to advance food and nutrition security: piloting a rapid assessment tool. Health Policy Plan 2015;30:566-78.

52. Meija-Costa A, Fanzo J. Fighting maternal and child malnutrition: analysing the political and institutional determinants of delivering a national multisectoral response in six countries. Brighton, UK: Institute of Development Studies, 2012.

53. Levinson FJ, Balarajan Y, Marini A. Addressing malnutrition multisectorally: what have we learned from recent international experience. New York, NY: UNICEF and MDG Achievement Fund, 2013.

54. Craig RL, Felix HC, Walker JF, et al. Public health professionals as policy entrepreneurs: Arkansas's childhood obesity policy experience. Am J Public Health 2010;100:2047-52.

55. Haddad L, Nisbett N, Barnett I, et al; Maharashtra's child stunting declines: what is driving them? Findings of a multidisciplinary analysis. Brighton, UK: Institute of Development Studies, 2014.

56. Hendriks AM, Delai MY, Thow AM, et al. Perspectives of fijian policymakers on the obesity prevention policy landscape. Biomed Res Int 2015;2015:1-10.

57. Kugelberg S, Jönsson K, Yngve A. Understanding the process of establishing a food and nutrition policy: the case of Slovenia. Health Policy 2012;107:91-7. 
58. Mosier SL. Cookies, candy, and coke: examining state sugarsweetened-beverage tax policy from a multiple streams approach. International Review of Public Administration 2013;18:93-120.

59. Thow AM, Swinburn B, Colagiuri S, et al. Trade and food policy: Case studies from three Pacific Island countries. Food Policy 2010;35:556-64.

60. Benson T. Cross-sectoral coordination failure: how significant a constraint in national efforts to tackle malnutrition in Africa? Food Nutr Bull 2007;28(Suppl):S323-30.

61. Gillespie S, van den Bold M, Hodge J, et al. Leveraging agriculture for nutrition in South Asia and East Africa: examining the enabling environment through stakeholder perceptions. Food Secur 2015;7:463-77.

62. Allender S, Gleeson E, Crammond B, et al. Moving beyond 'rates, roads and rubbish': How do local governments make choices about healthy public policy to prevent obesity? Aust New Zealand Health Policy 2009;6:20.

63. Ghartey AB. Nutrition policy and programs in Ghana: the limitation of a single sector approach. Washington, DC: World Bank, 2010.

64. Hill R, Gonzalez W, Pelletier DL. The formulation of consensus on nutrition policy: policy actors' perspectives on good process. Food Nutr Bull 2011;32(Suppl):S92-S104.

65. Acosta AM, Fanzo J. Fighting maternal and child malnutrition: analysing the political and institutional determinants of delivering a national multisectoral response in six countries. A synthesis paper. Brighton, UK: Institute of Development Studies, 2012.

66. Huicho L, Segura ER, Huayanay-Espinoza CA, et al. Child health and nutrition in Peru within an antipoverty political agenda: a countdown to 2015 country case study. Lancet Glob Health 2016;4:e414-26

67. Kennedy E, Tessema M, Hailu T, et al. Multisector Nutrition Program Governance and Implementation in Ethiopia: Opportunities and Challenges. Food Nutr Bull 2015;36:534-48.

68. Mohmand SK. Policies without politics: analysing nutrition governance in India. Brighton, UK: Institute of Development Studies, 2012.

69. van den Bold M, Kohli N, Gillespie S, et al. Is there an enabling environment for nutrition-sensitive agriculture in South Asia? Stakeholder perspectives from India, Bangladesh, and Pakistan. Food Nutr Bull 2015;36:231-47.

70. Taylor L. Analysing nutrition governance: Zambia country report. Brighton, UK: Institute of Development Studies, 2012.

71. Hawkes C, Ahern AL, Jebb SA. A stakeholder analysis of the perceived outcomes of developing and implementing England's obesity strategy 2008-2011. BMC Public Health 2014:14:441.

72. Sodjinou R, Bosu WK, Fanou N, et al. A systematic assessment of the current capacity to act in nutrition in West Africa: cross-country similarities and differences. Glob Health Action 2014:7:24763.

73. Henderson J, Coveney J, Ward P, et al. Governing childhood obesity: framing regulation of fast food advertising in the Australian print media. Soc Sci Med2009;69:1402-8.

74. Jenkin G, Signal L, Thomson G. Nutrition policy in whose interests? A New Zealand case study. Public Health Nutr 2012;15:1483-8.

75. Nathan SA, Develin E, Grove N, et al. An Australian childhood obesity summit: the role of data and evidence in 'public' policy making. Aust New Zealand Health Policy 2005;2:17.

76. Chung A, Shill J, Swinburn B, et al. An analysis of potential barriers and enablers to regulating the television marketing of unhealthy foods to children at the state government level in Australia. BMC Public Health 2012;12:1123.

77. Jou J, Niederdeppe J, Barry CL, et al. Strategic messaging to promote taxation of sugar-sweetened beverages: lessons from recent political campaigns. Am J Public Health 2014;104:847-53.

78. Mialon M, Swinburn B, Wate J, et al. Analysis of the corporate political activity of major food industry actors in Fiji. Global Health 2016;12:18

79. Moise N, Cifuentes E, Orozco E, et al. Limiting the consumption of sugar sweetened beverages in Mexico's obesogenic environment: a qualitative policy review and stakeholder analysis. J Public Health Policy 2011;32:458-75.
80. Shill J, Mavoa H, Allender S, et al. Government regulation to promote healthy food environments--a view from inside state governments. Obes Rev 2012;13:162-73.

81. Crammond B, Van C, Allender S, et al. The possibility of regulating for obesity prevention--understanding regulation in the commonwealth Government. Obes Rev 2013;14:213-21.

82. Ulijaszek SJ, McLennan AK. Framing obesity in UK policy from the Blair years, 1997-2015: the persistence of individualistic approaches despite overwhelming evidence of societal and economic factors, and the need for collective responsibility. Obes Rev 2016;17:397-411.

83. Jones E, Eyler AA, Nguyen L, et al. It's all in the lens: differences in views on obesity prevention between advocates and policy makers. Child Obes 2012;8:243-50.

84. Pérez-Ferrer C, Lock K, Rivera JA. Learning from international policies on trans fatty acids to reduce cardiovascular disease in low- and middle-income countries, using Mexico as a case study. Health Policy Plan 2010;25:39-49.

85. Sneyd A, Legwegoh AF, Sneyd LQ. Food politics: perspectives on food security in Central Africa. Journal of Contemporary African Studies 2015;33:141-61.

86. Levitt EJ, Pelletier DL, Pell AN. Revisiting the UNICEF malnutrition framework to foster agriculture and health sector collaboration to reduce malnutrition: a comparison of stakeholder priorities for action in Afghanistan. Food Policy 2009;34:156-65.

87. Taylor SA, Perez-Ferrer C, Griffiths A, et al. Scaling up nutrition in fragile and conflict-affected states: the pivotal role of governance. Soc Sci Med2015;126:119-27.

88. Walls HL, Cornelsen L, Lock K, et al. How much priority is given to nutrition and health in the EU Common Agricultural Policy? Food Policy 2016;59:12-23.

89. Sonnino R, Lozano Torres C, Schneider S. Reflexive governance for food security: The example of school feeding in Brazil. J Rural Stud 2014;36:1-12.

90. Yeatman HR. Food and nutrition policy at the local level: key factors that influence the policy development process. Crit Public Health 2003:13:125-38.

91. Wu M. Making nutrition policy central to development: understanding the political and institutional conditions for policy change: case study of the political economy of nutrition policies in Ethiopia. Washington, DC: World Bank, 2009.

92. Hodge J, Herforth A, Gillespie S, et al. Is there an enabling environment for nutrition-sensitive agriculture in East Africa? Stakeholder perspectives from Ethiopia, Kenya, and Uganda. Food Nutr Bull 2015;36:503-19.

93. Meerman J. Making nutrition a national priority - review of policy process in developing countries and case study on Malawi. Rome, Italy: Food and Agriculture Organization of the United Nations, 2008.

94. Vallgårda S, Nielsen ME, Hartlev M, et al. Backward- and forwardlooking responsibility for obesity: policies from WHO, the EU and England. Eur J Public Health 2015;25:845-8.

95. Young I, Gropp K, Pintar K, et al. Experiences and attitudes towards evidence-informed policy-making among research and policy stakeholders in the Canadian agri-food public health sector. Zoonoses Public Health 2014:61:503-89.

96. Monterrosa EC, Campirano F, Tolentino Mayo L, et al. Stakeholder perspectives on national policy for regulating the school food environment in Mexico. Health Policy Plan 2015;30:28-38.

97. Clarke B, Swinburn B, Sacks G. The application of theories of the policy process to obesity prevention: a systematic review and meta-synthesis. BMC Public Health 2016;16:1084.

98. Morris SS, Cogill B, Uauy R, et al. Effective international action against undernutrition: why has it proven so difficult and what can be done to accelerate progress? Lancet 2008;371:608-21.

99. Meadows DH. Thinking in systems: a primer. Hartford, VT: Chelsea Green Publishing, 2008.

100. Young H, Maxwell D. Participation, political economy and protection: food aid governance in Darfur, Sudan. Disasters 2013;37:555-78. 